\title{
O PODER PUNITIVO E AS TECNOLOGIAS DE GENÊRO: leituras pós-estruturais
}

\section{The punitive power and the technologies of gender: poststructural readings}

Rafael Martins de Meneses ${ }^{1}$

Tiago Alves de Jesus Barreto ${ }^{2}$

Letícia Carolina Pereira do Nascimento 3

RESUMO: Friedrich Nietzsche (2016) escreveu sobre a formação dos valores morais e de que maneira se cria a ideia de "bem" e "mal". Michel Foucault (2010; 2018; 2019) nos apresenta a ideia das tecnologias da sexualidade e noções sobre as engrenagens do saber-poder. Doravante, a presente pesquisa bibliográfica apresenta algumas co(i)nfluências desses teóricos na análise do sistema punitivo e nas tecnologias de gênero. Nessas leituras, percebe-se que o sujeito é uma criação que se desenrola dentro de discursos políticos moralizantes pulverizados nas teias sociais. O poder punitivo está para além do Direito Penal, ele é incorporado na naturalização e universalização do "bem" e "mal". Os instrumentos da anatomia política instauraram os valores de verdade e da moral, logo, afetando os campos de subjetividade, personalidade e consciência, por exemplo. Dito isso, podemos problematizar os dispositivos da moralidade, enfatizando àqueles normalizadores do gênero e da sexualidade. $\mathrm{Na}$ busca por mais pistas sobre esses problemas, também usaremos como referência Teresa de Lauretis (1994) e Judith Butler (2003). Nesse âmbito, entendemos que a produção discursiva pode operar diametralmente na emancipação da subjugação, na medida em que cria campos de existências para além das infames estruturas de opressão.

Palavras-chaves: Moral. Tecnologias de Gênero. Poder Punitivo.

\begin{abstract}
Friedrich Nietzsche (2016) wrote about the formation of moral values and how the idea of "good" and "evil" is created. Michel Foucault (2010; 2018; 2019) presents us with the idea of sexuality technologies and ideas about the gears of know-how. Henceforth, this bibliographic research presents some co(i)nfluences of these theorists in the analysis of the punitive system and in gender technologies. In these readings, it is perceived that the subject is a creation that unfolds within moralizing political discourses sprayed on social iats. Punitive power is beyond criminal law, it is incorporated into the naturalization and universalization of "good" and "evil". The instruments of political anatomy established the values of truth and morals, therefore affecting the fields of subjectivity, personality and consciousness, for example. That said, we can problematize the devices of morality, emphasizing those normalizers of gender and sexuality. In the search for more clues about these problems, we will also use as a reference Teresa de Lauretis (1994) and Judith Butler (2003). In this context, we understand that discursive

\footnotetext{
${ }^{1}$ Graduando em Bacharelado em Direito pela Universidade Federal do Piauí. E-mail: rafaelmartinsm98@gmail.com

2 Graduando em Bacharelado em Direito - Universidade Federal do Piauí (UFPI), e-mail: tiagoalves_99_@hotmail.com 3 Professora da Universidade Federal do Piaú (UFPI), Doutoranda em Educação (UFPI). E-mail:
lecarolpereira@gmail.com
} 
production can operate diametrically in the emancipation of subjugation, to the extent that it creates fields of existence beyond the infamous structures of oppression.

Key-words: Moral. Gender Technologies. Punitive Power.

\section{INTRODUÇÃO}

O presente texto apresenta ressonâncias filosóficas entre Friedrich Nietzsche (2016), Michel Foucault (2010; 2018; 2019), Teresa de Lauretis (1994) e Judith Butler (2003) para refletir sobre o poder punitivo no que tange as tecnologias de gênero. As referências que atravessam a tessitura desse texto estão ramificadas de diferentes modos no rizoma pós-estruturalista que questiona a concepção de sujeito humanista numa perspectiva pulverizada das relações de poder e de produções discursivas.

Metodologicamente optamos por levantamento bibliográfico de modo a traçar possível caminhos para uma reflexão genealógica de moral, poder e tecnologias de gênero, menos do que esgotar os temas, pretendemos contribuir com o debate de modo a questionar estruturas enrijecidas que produzem violências. De modo ensaístico inicialmente introduziremos alguns conceitos iniciais para pensar a moral e o poder respectivamente em Nietzsche e Foucault para depois pensar as tecnologias com atravessamentos de autoras que cruzam as dimensões feministas.

\section{LEITURAS NIETZSCHEANAS SOBRE A MORAL}

Há um conflito constante entre as relações sociais, conflito este que influenciará, a própria realidade discursiva e as relações de poderes compreendidas culturalmente. Isso quer dizer que a ação de nomear corpos, assim com as coisas que nos cercam, constitui numa atribuição de valor a existência desse mesmo ser. Esse processo, embora inevitável à civilização, acarreta em diversas dinâmicas discriminatórias e de negação da própria vida, na medida em que possivelmente limita o potencial de existência que muitos corpos poderiam dar a si mesmos e, sofisticando essa ideia, constituindo institucionalmente uma hierarquia de sujeitos. Friedrich Nietzsche, afirmando um método genealógico de pesquisa, faz um estudo a respeito dos valores vigentes na civilização ocidental, buscando uma historicidade, ou seja, os processos de construção de cada uma dessas categorias morais: o bom e o mau. Nas palavras do autor:

Agora está bem claro para mim que, a partir dessa teoria, a verdadeira fonte do conceito de "bom" é procurada e oposta no lugar errado: o julgamento "bom" não provém daqueles que demonstram bondade! Em vez disso, foram os 
próprios "bons", ou seja, os nobres, poderosos, superiores em posição de pensamento, que sentiram e estabeleceram a si próprios e a suas ações como bons, isto é, como algo de primeira categoria, em contraste a tudo que fosse mesquinho, inescrupuloso, vulgar e plebeu. Partindo desse Pathos da distância, eles se atribuíram o direito de criar valores, nomeá-los: a utilidade não thes importava! (NIETZSCHE, 2016, p. 19).

O autor elabora a abordagem genealógica sobre a formação dos valores morais e de que maneira se cria a ideia de "bem" e "mal". No entendimento do filósofo, a criação de valores surge de uma tensão existente entre corpos que se identificam e exercem a afirmação de si mesmos (de sua própria criação). Contudo, nesse mesmo processo de criação, existe uma ação que vem em contrapartida ao criativo, e esta é nomeada de ressentimento. De maneira sucinta, o ressentimento pressupõe a imediata negação de qualquer criação do outro e tentativa de desvinculação. Uma moralidade baseada na negação dos processos criativos só pode afirmar a si mesma, e exige a submissão de toda a realidade sob os seus valores. $\mathrm{Na}$ medida em que um grupo decide limitar por si e por outros de que maneira proceder-se-ão as regras, a criação de papéis, a própria linguagem, imediatamente está-se criando hierarquias, classificações do mundo e consequentemente discriminações dos corpos.

A visão colocada por Nietzsche (2016) sobre a construção dos valores morais da nossa civilização ocorre, portanto, em duas ações distintas: primeiramente temos o ato criativo, o qual ele valoriza de maneira positiva, e, posteriormente, o surgimento dos valores do ressentimento no meio desse processo, os quais são baseados na negação das mudanças, na negação do outro e no desejo de vingança a tudo que opera de maneira afirmativa da vida. Mas esse conflito de forças que irão formatar a vida em sociedade passará a operar de maneira cada vez mais articulada, onde o ser humano é influenciado por um contexto espaço-temporal, pelas próprias limitações da linguagem, e afinal

[...] descobrimos que tampouco este ser pode ser responsável, na medida em que é inteiramente uma consequência necessária e se forma a partir dos elementos influxos de coisas passadas e presentes: portanto, que não se pode tornar o homem responsável por nada, seja por seu ser, por seus motivos, por suas ações ou por seus efeitos. (NIETZSCHE, 2016, p. 45).

A pessoa não possui responsabilidade autônoma para reger a si, uma vez que várias articulações determinantes na sua existência. A limitação do "bem" e do "mal" impregnada nos símbolos esconde em si própria um ato de opressão. Limitar remete a excluir possibilidades indesejadas. Partindo da abstração linguística, ou seja, a essência colocada nas coisas que identificamos com nossos símbolos, as condutas individuais são guiadas, assim como as relações de poder e o desenvolvimento das instituições. 
Para Nietzsche (2016), a história dos sentimentos morais se divide em fases. Primeiramente classificam-se em boas ou más ações isoladas, considerando apenas suas consequências práticas hipotéticas, qualificando-as como úteis ou prejudiciais. Contudo, com a naturalização do entendimento de determinadas ações como "bem" e "mal", não se pensa mais nas consequências, mas apenas na ação isolada que já está simbolicamente carregada de sentimentos.

Em seguida, transfere-se o entendimento, a qualificação aos motivos da ação, portanto observando que os atos morais podem ser ambíguos a depender da situação aplicada. Mas acredita-se que os motivos partem inteiramente do próprio indivíduo, portanto, nessa última fase, os predicados "bem" e "mal” são aplicados à pessoa, que agora de maneira lógica passa a ser um "sujeito do bem" ou "sujeito do mal". Enraizar os motivos no próprio indivíduo, como se ele possuísse pleno controle e liberdade de projetar seus sentimentos e ações no mundo, é negar a complexidade da subjetividade humana.

Para difundir uma conduta moral dominante, pode-se utilizar as ferramentas da punição. Friedrich Nietzsche (2016), ao analisar o castigo, percebe uma similaridade de significados com a relação entre quem deve e quem compra. Há um sentimento de dívida entre o indivíduo transgressor das regras e a sociedade, portanto, precisando restituir de alguma maneira o dano causado. A partir dessa relação forjada nos fundamentos da relação credor/a-devedor/a surge o castigo: uma maneira de converter o dano causado em dor ao/à causador/a.

Mediante o "castigo" ao devedor, o credor toma parte no direito dos senhores; por fim, ele chega a experimentar o exaltado sentimento de desprezar e maltratar uma criatura como "inferior" - ou, pelo menos, vê-la desprezada e maltratada no caso de a efetiva violência punitiva, a aplicação da pena, ter sido passada à "autoridade". (NIETZSCHE, 2016, p. 58).

O castigo como multa, ressarcimento do dano, servidão, eliminação do elemento causador, escárnio da pessoa inimiga, reclusão forçada, a vingança, a declaração de guerra contra quem é inimigo/a da paz, são todas maneiras do tecido social cobrar aquilo que o/a infrator/a supostamente a deve. Entre as muitas utilidades esperadas do castigo, certamente fazer com que o indivíduo reconheça o seu erro e sinta remorso da sua ação é o interesse de todas elas. O castigo é legitimado por uma moral coercitiva, pois a moralidade é antecedida da coerção, "[...] e ela mesma é ainda por algum tempo coerção, à qual a pessoa se acomoda para evitar desprazer. Depois ela se torna costume, mais tarde obediência livre, e finalmente quase instinto" (NIETZSCHE, 2005, p.71). A culpa representa o sentimento de submissão do indivíduo que uma vez transgrediu limites dos valores convencionados. A culpa pretende causar um sentimento de inferioridade. Ao produzir as leis das condutas (in)desejadas a moral vai operando na construção de ideais positivos e negativos e, consequentemente, no exercício do poder sobre si. 
A sociedade ocidental, em especial a moralidade judaico-cristã, está fundada sobre a exaltação do sentimento de culpa, que pressupõe a necessidade de provocar arrependimento por meio da punição (NIETZSCHE, 2010). Essa moralidade cria a justiça retributiva, provoca o alívio psicológico ao contemplar o castigo do "homem mal", infecta a própria estrutura cognitiva do ser humano num ciclo destrutivo de punições, culpa e a ilusão da redenção pela dor. Acreditase que pelo castigo estaremos purificando, protegendo e garantindo a justiça, uma ideia bastante conturbada e que se volta destrutivamente contra o próprio sujeito cujo a exige.

O processo de construção dos valores dentro de uma comunicação civilizatória, para Nietzsche (2016) é algo em constante destruição e construção, portanto trata-se de um processo inerente à civilização atrelado a um jogo de forças que impulsionam a expansão dos valores em direção à vida. No entanto, esse processo veio a acontecer no ocidente de duas maneiras possíveis, segundo o filólogo. A primeira delas vem com a instituição natural de valores afirmativos, que só vem por meio do conflito entra a multiplicidade criativa humana em um contexto de interdependência. Esse conflito se mostra como afirmativo da vida na medida em que pretende sempre a expansão do humano como ser passageiro no mundo, portanto dependentes uns dos outros, ao mesmo tempo em que se manifesta como animal produtor de linguagem.

O segundo processo que surge se dá pela moral do ressentimento. Um processo reacionário de negação da vida. Nesse contexto ele habilita o cristianismo, a filosofia de Sócrates em diante, etc. O processo de invenção dos valores morais da plebe se dá pela exclusão do próprio conflito inerente ao processo de vida, o mesmo conflito responsável pela expansão e construção de novos valores. De que maneira isso acontece? Um dos principais pontos que Nietzsche (2016) vai colocar é a ideia de verdade como algo uno/perfeito/divino, é sobre essas ideias que a filosofia e a religião se construíram no decorrer da história ocidental. Contudo, negam o fato de elas próprias serem parte do processo de invenção dos valores e do próprio conhecimento. Quanto ao corpo: é através dos corpos que as forças se expandem ou se anulam.

\section{LEITURAS FOUCAULTIANAS DO PODER E SEXUALIDADE}

Michel Foucault (2010a) dedica-se a estudar e entender a ideia de poder dentro da sociedade, a maneira como se conforma, buscas históricas diversas e crítica às instituições. Segundo o pensador francês, o poder produz saber, e que ambos estão diretamente interligados, desse modo 
Temos antes que admitir que o poder produz saber (e não simplesmente favorecendo-o porque o serve ou aplicando-o porque é útil); que poder e saber estão diretamente implicados; que não há relação de poder sem constituição correlata de um campo de saber, nem saber que não suponha e não constitua ao mesmo tempo relações de poder. Essas relações de "poder-saber" não devem então ser analisadas a partir de um sujeito do conhecimento que seria ou não livre em relação ao sistema do poder; mas é preciso considerar ao contrário que o sujeito que conhece, os objetos a conhecer e as modalidades de conhecimentos são outros tantos efeitos dessas implicações fundamentais do poder-saber e de suas transformações históricas. Resumindo, não é a atividade do sujeito de conhecimento que produziria um saber, útil ou arredio ao poder, mas o poder-saber, os processos e as lutas que o atravessam e que o constituem, que determinam as formas e os campos possíveis do conhecimento. (FOUCAULT, $2010^{a}$, p. 30).

Isso quer dizer que uma relação de poder, inevitavelmente está a criar um entendimento de mundo, ou seja, moldar a realidade, de acordo com os valores que a sustentam. Não basta que esse conhecimento seja compreendido apenas por quem exerce o poder dominante, mas ele precisa ser absolvido, ou pelo menos legitimado. Ressalta-se aqui que a instauração de um saberpoder não exclui a existência de outras formas discursivas e políticas, todavia, opera na hierarquização dos campos de poder-saber e na sua consequente sobreposição. O poder não se instaura na unanimidade, mas sim na criação da ilusão de um corpo social que só funcionará de maneira saudável se mecanismos de sua preservação forem instaurados no controle dos corpos.

Eu acho que o grande fantasma é a ideia de um corpo social constituído pela universalidade das vontades. Ora, não é o consenso que faz surgir o corpo social, mas a materialidade do poder se exercendo sobre o próprio corpo dos indivíduos. (FOUCAULT, 2019, p. 31).

A instauração de um poder punitivo não se fez meramente na pena pelo sofrimento, embora essa ainda hoje esteja presente, mas através da vigilância, disciplina e meios mais sutis de exercer controle. O poder punitivo aqui deve ser entendido para além da sua expressão jurídicopositiva que é o Direito Penal. Ele é incorporado nas relações sociais, na naturalização do bem e mal universalizados e prende os corpos com discursos (FOUCAULT, 2010; NIETZSCHE, 2016).

Quais são os outros campos de saber-poder? Quais conhecimentos sobre a punição, culpa e moral são produzidos ou inibidos? O que a materialidade e a força dos corpos das pessoas tidas como infames pode nos ensinar sobre as tecnologias políticas do corpo? São indagações que precisam ser consideradas.

A quem interessa silenciar, impossibilitar e marginalizar os discursos e produções desses corpos? O suposto princípio de "em defesa da sociedade" acaba por encobrir outros processos, 
além das suspeitas normas coletivas defendidas pelas ideias sociais hegemônicas. Foucault (2010b), perspicazmente, denominará de saberes sujeitados aqueles conhecimentos eruditos ou desqualificados não correspondentes aos parâmetros definidos de cientificidade, conceituação, racionalidade, dentre outros requisitos de qualificação dos discursos. Os saberes produzidos por pessoas que fogem a essa moralidade e lógica hierarquizante entram nesse rol de saberes sujeitados e

[...] foi pelo reaparecimento desses saberes de baixo, desses saberes não qualificados, desses saberes desqualificados mesmo, foi pelo reaparecimento desses saberes: o do psiquiatrizado, o do doente, o do enfermo, o do médico, mas paralelo e marginal em comparação com o saber médico, o saber delinquente, etc. - esse saber denominarei, se quiserem, o "saber das pessoas" (e que não é de modo algum um saber comum, um bom senso, mas, ao contrário, um saber particular, um saber local, regional, um saber diferencial, incapaz de unanimidade e que deve sua força apenas à contundência que opõe a todos aqueles que o rodeiam) -, foi pelo reaparecimento desses saberes locais das pessoas, desses saberes desqualificados, que foi feita a crítica. (FOUCAULT, 2010b, p. 8-9).

Assim os saberes sujeitados ou das pessoas possibilitaram a elaboração da crítica genealógica, que busca questionar às inferiorizações e a unanimidade dos conhecimentos e poderes. Essas revoluções político-epistemológicas são emergentes para as comunidades historicamente subrepresentadas, a difusão de modos locais de reconhecimento da realidade circundante é uma estratégia e tática de (sobre)vivência nos atuais cenários de disputa de podersaber.

Dentro desse debate, possibilidade e impossibilidade são noções de existência moldadas pelas discursividades, Foucault (2016) entende os movimentos históricos como construtores da moral e de verdades, essa construção histórica promove modelos de existência com tendência de universalidade. A corporalidade, em especial, quanto às questões moralizantes sobre/do/sob o gênero e a sexualidade, é afetada por discursos históricos que enquadram os seus saberes e poderes.

Quando analisamos o campo de saber-poder dos gêneros e sexualidades, estamos adentrando em construções biojurídicossociais. São processos interdisciplinares, demandantes de intersecções entre áreas, em geral, estudadas independentemente. Evocamos Michel Foucault (2018, p. 42) ao afirmar que na história do ocidente "as proibições relativas ao sexo eram, fundamentalmente, de natureza jurídica", nesse modelo, as alegações contra natureza na verdade traduziam uma forma extrema de contra a lei. Cabe ressaltar que os discursos sobre o sexo nunca foram pacificados, sua multiplicidade semântica acarreta em usos controversos, longe de ser unânime sua utilização, mesmo no século XXI, onde 


\begin{abstract}
O importante nessa história não está no fato de terem tapado os próprios olhos ou os ouvidos, mesmos, é, primeiro, que tenha sido construído em torno do sexo e a propósito dele um imenso aparelho para produzir a verdade, mesmo que para mascarála no último momento. O importante é que o sexo não tenha sido somente objeto de sensação e de prazer, de lei ou de interdição, mas também de verdade e falsidade, que a verdade do sexo tenha se tornado coisa essencial, útil ou perigosa, preciosa ou temida; em suma, que o sexo tenha sido constituído em objeto de verdade. Deve-se, portanto, considerar não o limiar de uma nova racionalidade, que a descoberta de Freud ou de outro tenha marcado, mas a formação progressiva (e também as transformações) desse "jogo da verdade e do sexo" que o século XIX nos legou, e do qual nada prova, mesmo que o tenhamos modificado, estarmos liberados. Desconhecimentos, subterfúgios, esquivas só foram possíveis e só tiveram efeito baseados nessa estranha empresa: dizer a verdade do sexo. Empreendimento que não data do século XIX, mesmo se o projeto de uma "ciência" lhe emprestou, então, forma singular. Ele é o pedestal de todos os discursos aberrantes, ingênuos e ardilosos em que o saber sexual parece ter, durante tanto tempo, se extraviado. (FOUCAULT, 2018, p. 63).
\end{abstract}

Pelas provocações do autor supracitado é possível ampliar a análise da sexualidade, comumente generalizada somente na esfera do prazer e da anatomia. O saber sexual, conforme a perspectiva foucaultiana apresentada, trata-se de um arcabouço político-epistêmico disputado e possui grande contribuição na produção da subjetividade e subjetivação do ocidente. No jogo da verdade do sexo, muitos desdobramentos discursivos atuam: psicologia, biologia, política, religião, sociologia, filosofia, direito, dentre outras áreas. Nesse cenário, dizer a verdade do sexo é uma competição que não se desenvolveu somente na atualidade, compreende-se a importância de enfatizar seu processo durante a história humana e encontrar, assim, pistas de como esse processo se fez e faz.

$\mathrm{Na}$ construção do saber-poder sexual, Foucault (2018) chama de tecnologias da sexualidade esses empreendimentos de subjetivação operantes nas corporalidades e suas (im)possibilidades. Por vezes, essa empreitada em busca da definição da verdade do sexo utilizase dos discursos científicos para sofisticar seu exercício de saber-poder. As reações a essas definições sem unanimidade relacionam-se aos saberes subalternizados, nas existências infames que reorganizam seus territórios subjetivos em uma diferenciação contra hegemônica.

\title{
4. LEITURAS ENTRE NIETZSCHE E FOUCAULT: DISPOSITIVOS DA MORALIDADE
}

Os dispositivos de poder-saber utilizam, às vezes sutilmente, da disciplina, que tende a alcançar o status de instinto, virtude e verdade, nos termos nietzscheanos. É necessário destacar o caráter imanente que envolve esse fenômeno. Assim, o poder é diluído pelo o corpo, através da alma, como Foucault (2010a, p. 32) propõe 
Não se deveria dizer que a alma é uma ilusão, ou um efeito ideológico, mas afirmar que ela existe, que tem uma realidade, que é produzida permanentemente, em torno, nas superfícies, no interior do corpo pelo funcionamento de um poder que se exerce sobre os que são punidos - de maneira mais geral sobre os que são vigiados, treinados e corrigidos, sobre os loucos, as crianças, os escolares, os colonizados, sobre os que são fixados a um aparelho de produção e controlados durante a sua existência.

Por sua vez, Nietzsche (1885), em um fragmento póstumo, afirma que

Tomar o corpo como ponto de partida e fazer dele o fio condutor, eis o essencial. O corpo é um fenômeno mais rico que autoriza observações mais claras. A crença no corpo é bem melhor estabelecida do que a crença no espírito. (NIETZSCHE, agosto-setembro 1885, 40 [15] apud BARRENECHEA, 2011, p. 3).

As assertivas de Foucault (2010a) mesclam a crítica de Nietzsche $(1885 ; 2018)$ a toda filosofia metafísica do pensamento idealista, desde Parmênides até Kant, que evocavam a alma e o espírito como a essência humana em detrimento e esquecimento do corpo. Foucault (2010a), ao falar da existência da alma, não contraria a imanência nietzscheana, uma vez que aquele entende que a alma e o corpo possuem uma relação real. O corpo possibilita a produção de uma alma que funciona pelo poder, ou seja, a pretensa metafísica associada a alma é desconstruída em uma imanência corporal, assim

Esta alma real e incorpórea não é absolutamente substância; é o elemento onde se articulam os efeitos de um certo tipo de poder e a referência de um saber, a engrenagem pela qual as relações de poder dão lugar a um saber possível, e o saber reconduz e reforça os efeitos de poder. Sobre essa realidade-referência, vários conceitos foram construídos e campos de análise foram demarcados: psique, subjetividade, personalidade, consciência, etc.; sobre ela técnicas e discursos científicos foram edificados; a partir dela, valorizaram-se as reivindicações morais do humanismo. Mas não devemos nos enganar: a alma, ilusão dos teólogos, não foi substituída por um homem real, objeto de saber, de reflexão filosófica ou de intervenção técnica. O homem de que nos falam e que nos convidam a liberar já é em si mesmo o efeito de uma sujeição bem mais profunda que ele. Uma 'alma' o habita e o leva à existência, que é ela mesma uma peça no domínio exercido pelo poder sobre o corpo. A alma, efeito e instrumento de uma anatomia política; a alma, prisão do corpo. (FOUCAULT, 2010a, p. 32).

Não se trata, então, de uma ontologização da alma, uma essência natural e atemporal, mas sim, um constante agenciamento histórico contingencial de engendramento das tecnologias políticas, dentre elas as da sexualidade, em que percorre essa alma encarnada (SILVEIRA, 2003). Esse instrumento da anatomia política instaurou os valores de verdade e da moral, logo, os campos de subjetividade, personalidade e consciência, por exemplo, estão demarcados por essa 
realidade-referência. Para Nietzsche (2012) a consciência é intermitente e construída, em uma de suas críticas assevera que

Tomam a consciência por uma firme grandeza dada! Negam seu crescimento, suas intermitências! Veem-na como "unidade do organismo"! - Essa ridícula superestimação e má-compreensão da consciência tem por corolário a grande vantagem de que assim foi impedido o seu desenvolvimento muito rápido. (NIETZSCHE, 2012, p. 90).

As prisões do/no corpo englobam diversos meios de atuação, essa multiplicidade é coordenada pelas técnicas políticas do corpo, nas quais Foucault (2010, p. 29) afirma existir "uma microfísica do poder posta em jogo pelos aparelhos e instituições, mas cujo campo de validade se coloca de algum modo entre esses grandes funcionamentos e os próprios corpos com sua materialidade e suas forças". Nesse ponto, podemos articular a formação da consciência, através da culpa e arrependimento, como parte das engrenagens controladas pelas técnicas políticas do corpo, uma vez que se apresentam como elementos de docilização dos corpos.

Ao verificar as estratégias, manobras, táticas, construídas por essa microfísica do poder, não afirmamos a total subordinação da população: crianças, pacientes, discentes, detentas/os e todos os grupos envoltos em relações de poder. Outrossim, buscamos analisar os mecanismos de validação dessa microfísica e evidenciar os movimentos de fissuras, (in)subordinações de resistência, desobediências epistemológicas e políticas. Dito isso, podemos problematizar os dispositivos da moralidade, enfatizando àqueles normalizadores do gênero e da sexualidade.

\section{LEITURAS PÓS-ESTRUTURAIS DAS TECNOLOGIAS DE GÊNERO}

Por estar sempre em disputa, sexo torna-se um conceito transversal, podendo assumir o significado de gênero (não-binário, feminino, masculino e outras expressões), distinção cromossômica (XXY, XY, XX e outras variações genéticas) e, frequentemente, confunde-se com orientação sexual (Lésbica, Bissexual, Gay). Entendemos o sexo como potente elo de articulação entre as teorias e utilizações, buscando tensioná-lo com gênero e sexualidade, uma vez que esses dispositivos estão em coalisão.

Parece-nos contraproducente o colóquio acerca da hierarquia e anterioridade dos dispositivos, tendo em vista a pluralidade de suas direções e exteriorizações, sendo mais urgente analisar a situacionalidade em que se materializam, pois são, sobretudo, dispositivos de poder. Foucault $(2018$, p. 91) aponta a relação negativa do poder-sexo, que se dá pela instância da regra: 
"O poder age pronunciando a regra: o domínio do poder sobre o sexo seria efetuado através da linguagem, por um ato de discurso que criaria, pelo próprio fato de enunciar, um estado de direito". A partir dessas reflexões podemos ver as bifurcações do poder-sexo.

Nas lacunas de saber-poder, surgem novas possibilidades discursivas, novas resistências específicas de corpos insubordinados, onde "As mulheres, os prisioneiros, os soldados, os doentes nos hospitais, os homossexuais iniciaram uma luta específica contra a forma particular de poder [...] que se exerce sobre eles.” (FOUCAULT, 2019, p. 141). Os saberes sobre esses corpos, em especial, nas construções de gênero, perpassam por diversos locais, desde as escolas até as rodas de sociabilidade. Essa constituição de si se mostra enraizada em um rizoma conceitual de saber-desejo-gênero, pois

Explicar as categorias fundacionais de sexo, gênero e desejo como efeitos de uma formação específica de poder supõe uma forma de investigação crítica, a qual Foucault, reformulando Nietzsche, chamou de "genealogia". A crítica genealógica recusa-se a buscar as origens do gênero, a verdade íntima do desejo feminino, uma identidade sexual genuína ou autêntica que a repressão impede de ver; em vez disso, ela investiga as apostas políticas, designando como origem e causa categorias de identidade que, na verdade, são efeitos de instituições, práticas e discursos cujos pontos de origem são múltiplos e difusos. (BUTLER, 2015, p. 9-10).

As genealogias feitas por Foucault, inspiradas no filósofo alemão Friedrich Nietzsche, apresentam inéditas abordagens para a análise da construção dos discursos, priorizando o específico e descontínuo, não a progressão linear e/ou continuidade (SPARGO, 2017). A perspectiva genealógica promove a desmistificação do funcionamento de modelos universais. Nesse viés genealógico adotamos o conceito de tecnologia de gênero, de maneira que

[...] pode-se começar a pensar o gênero a partir de uma visão teórica foucaultiana, que vê a sexualidade como uma "tecnologia sexual"; desta forma, propor-se-ia que também o gênero, como representação e como autorepresentação, é produto de diferentes tecnologias sociais, como o cinema, por exemplo, e de discursos, epistemologias e práticas críticas institucionalizadas, bem como das práticas da vida cotidiana. Poderíamos dizer que, assim como a sexualidade, o gênero não é uma propriedade de corpos nem algo existente a priori nos seres humanos, mas, nas palavras de Foucault, 'o conjunto de efeitos produzidos em corpos, comportamentos e relações sociais', por meio do desdobramento de 'uma complexa tecnologia política'. (LAURETIS, 1994, p. 208).

Essa discussão perpassa pelas noções de desvio de padrão e o uso das leis como mecanismo de controle dos corpos. Nisto, o poder não é exclusivo do sistema judiciário em sua 
extensão punitiva, o poder é exercido também por meio de outras instituições a partir do controle, da vigilância, da normatização. Desse modo

O poder, ao invés da lei, abrange tanto as funções ou relações diferenciais jurídicas (proibitivas e reguladoras) como as produtivas (inintencionalmente generativas). Consequentemente, a sexualidade que emerge na matriz das relações de poder não é uma simples duplicação ou cópia da lei ela mesma, uma repetição uniforme de uma economia masculinista da identidade. As produções se desviam de seus propósitos originais e mobilizam inadvertidamente possibilidades de "sujeitos" que não apenas ultrapassam os limites da inteligibilidade cultural como efetivamente expandem as fronteiras do que é de fato culturalmente inteligível. (BUTLER, 2015, p. 63).

Judith Butler (2015) discorre que as culturas sempre criam inteligibilidades por meio de produções e relações jurídicas. As relações jurídicas podem se dividir pelas suas funções proibitivas e reguladoras, em contramão, as performances humanas produzem outras possibilidades em consonância ou não com a inteligibilidade imposta. Reiterando o exposto, Teresa de Lauretis (1994) indica que

[...] a construção do gênero ocorre hoje através das várias tecnologias do gênero (p. ex., o cinema) e discursos institucionais (p. ex., a teoria) com poder de controlar o campo do significado social e assim produzir, promover e "implantar" representações de gênero. Mas os termos para uma construção diferente do gênero também existem, nas margens dos discursos hegemônicos. Propostos de fora do contrato social heterossexual, e inscritos em práticas micropolíticas, tais termos podem também contribuir para a construção do gênero e seus efeitos ocorrem ao nível "local" de resistências, na subjetividade e na auto-representação. (LAURETIS, 1994, p. 228).

Como exemplo, temos as normas sociais para a família e a regra da reprodução sexual, onde presume-se o ideal de um casal heterossexual e fértil com o propósito de procriar e gerar uma família. Geralmente, tal fórmula é apresentada como uma matriz social regulamentada juridicamente, assim, negligenciando a autonomia das pessoas em interpretar tais matrizes com rearranjos que ultrapassam os limites estabelecidos, essas ultrapassagens só existem por conta da falta da universalidade e ontologização desses limites. Nesse sentido

[...] o gênero não é um substantivo, mas tampouco é um conjunto de atributos flutuantes, pois vimos que seu efeito substantivo é performativamente produzido e imposto pelas práticas reguladoras da coerência do gênero. Consequentemente, o gênero mostra ser performativo no interior do discurso herdado da metafísica da substância — isto é, constituinte da identidade que supostamente é. Nesse sentido, o gênero é sempre um feito, ainda que não seja obra de um sujeito tido como preexistente à obra. No desafio de repensar as categorias do gênero fora da metafísica da substância, é mister considerar a relevância da afirmação de Nietzsche, em A genealogia da moral, de que "não 
há 'ser* por trás do fazer, do realizar e do tomar-se; o 'fazedor' é uma mera ficção acrescentada à obra - a obra é tudo”. (BUTLER, 2015, p. 56).

O pensamento da autora reformula a noção de construção no que diz respeito às relações de gênero e nos dá um direcionamento para um dos seus conceitos: o de performatividade, que está ligado ao processo de constituição de gênero, de como se internaliza as normas que estilizam os corpos e acrescenta que “ou o gênero está construído e não temos a dizer como vivemos o gênero ou o gênero é radicalmente eleito e podemos fazer o que queremos" (ALIAGA, 2008, p. 55, tradução nossa). Podemos dizer que estes corpos transgressores de gênero e da cisheteronormatividade não conformados ao padrão binário são marcados pela desigualdade de oportunidades e de respeito, mas "não se conformam, nunca completamente, às normas pelas quais sua materialização é imposta" (BUTLER, 1999, p. 154).

Assumindo notórios contornos de biopoder, a sexualidade passa a ser disciplinada para além dos espaços de confinamento ampliando seus tentáculos para todas as dimensões da vida humana. Segundo Preciado (2014), para Michel Foucault a forma mais eficaz de resistência à produção normativa da sexualidade em nossas sociedades não é o combate à proibição da sexualidade, “(como aquela proposta pelos movimentos de liberação sexual antirrepressivos dos anos setenta), e sim a contraprodutividade, isto é, a produção de formas de prazer-saber alternativas à sexualidade moderna" (PRECIADO, 2014, p. 22).

\section{LEITURAS FINAIS}

A partir das conexões entre Nietzsche e Foucault as sólidas estruturas da moral são abaladas de modo a compreender e questionar o processo de naturalização que oculta produções discursivas que normatizam nossas relações sociais. A moral diminui a potência criativa da humanidade moldando a realidade social, contudo, uma compreensão pulverizada de poder permite a emergência de rupturas. O poder, para além de punir, de fazer sofrer, também disciplina, vigia, e onde há poder, há resistência.

Faz parte dos jogos de poder os jogos da verdade, por isso a relação entre poder-saber é tão importante nesse debate, pois, nos permite entender como a produção discursiva produz epistemologias diversas que sustentam hierarquias sociais. É desse modo que a sexualidade é normatizada a partir de diferentes campos de conhecimento num jogo político-epistêmico de fabricação e fixação da cisheteronormatividade. As tecnologias da sexualidade atuam na produção de subjetividades e corporalidade dóceis, de modo que o controle da sexualidade transborda o próprio campo sendo central para a organização social do ocidente de modo geral. 
Entre os jogos de saber-poder a sexualidade não é produzida de modo definitivo, precisa sempre ser reiterada, a norma não cansa de se (re)produzida, por isso mesmo, ela por vezes escapa, desliza, transcende a forma que lhe é importa e configura outros corpos, outras subjetividades. Todas essas dissidências que fogem a inteligibilidade humana imposta pelo cisheteronormatividade são produzidas na relação com as normas. É preciso, nesse sentido, romper com o padrão naturalizante da cisheteronormatividade para compreender que todos os corpos são fabricados. Conclui-se afirmando a potência inventiva de vida que rompe com a moral e instaura processos de criação que transbordem imposições de sexo/gênero impostas.

\section{REFERÊNCIAS}

ALIAGA, Juan Vicente. Entrevista con Judith Butler: Interrogando el mundo. In: Exit Book: revista de libros de arte y cultura visual. no. 9, 2008, págs. 54-61. España: 2008. Disponível em: $<$ https://issuu.com/sinapsisdocuments/docs/10_regina_vogel>. Acessado em: 03 out. 2020.

BARRENECHEA, M. A. de. Nietzsche, corpo e subjetividade. In: Revista O percevejo Online, v. 3, no 2, agosto-dezembro, 2011. p. 1-18.

BUTLER, Judith. Problemas de gênero: Feminismo e subversão da identidade. $8^{a}$ ed. Rio de Janeiro: Civilização Brasileira, 2015.

FOUCAULT, M. Em defesa da sociedade: curso no Collège de France (1975-1976). $2^{\mathrm{a}}$ ed. São Paulo: Editora WMF Martins Fontes, 2010b.

FOUCAUlT, M. Microfísica do Poder. 9 ed. Rio de Janeiro/São Paulo: Paz \& Terra, 2019.

FOUCAUlT, M. Vigiar e Punir: Nascimento da prisão. 38 a ed. Petrópolis: Editora Vozes, 2010a.

FOUCAULT, M. A história da sexualidade I: a vontade de saber. São Paulo: Paz \& Terra, 2018.

FOUCAULT, M. Subjetividade e verdade. São Paulo: Martins Fontes, 2016.

LAURETIS, Teresa de. A tecnologia do gênero. In: HOLLANDA, Heloisa (Org.). Tendências

e impasses: o feminismo como crítica da cultura. Rio de Janeiro: Rocco, 1994. p. 206-241.

NIETZSCHE, F. A Gaia Ciência. 1 ed. São Paulo, Companhia das Letras, 2012. 
NIETZSCHE, F. Crepúsculo dos Ídolos: Como filosofar a marteladas.1 ed. São Paulo: Lafonte, 2018.

NIETZSCHE, F. Genalogia da moral: uma polêmica. 1. ed. Rio de Janeiro: Best Bolso, 2016.

NIETZSCHE, F. Humano, demasiado humano: Um livro para espíritos livres. 1. ed. São Paulo: Companhia de Letras, 2005.

PRECIADO, Paul B. Manifesto Contrassexual. Tradução de Maria Paula Gurgel de Oliveira. São Paulo: n-1 edições, 2014.

SILVEIRA, Fernando de Almeida; FURLAN, Reinaldo. Corpo e Alma em Foucault: Postulados para uma Metodologia da Psicologia. Psicol. USP, São Paulo, v. 14, n. 3, p. 171-194, 2003.

SPARGO, Tamsin. Foucault e a Teoria Queer: seguido de Àgape e êxtase: orientações pósseculares. Tradução: Heci Regina Candiani. 1 ed. Belo Horizonte: Autêntica Editora, 2017. 